\title{
The Digital Lifeworld and Salutogenesis
}

\author{
Luis Saboga-Nunes, Uwe H. Bittlingmayer, \\ and Pauline Bakibinga
}

\section{Introduction}

It has been said that the future is digital. The COVID-19 pandemic is just one pressing example of how digitalization of health care is transforming our societies with an intensity never experienced before (Whitelaw et al., 2020). This crisis has also been a unique opportunity to consider how health promotion has been actively involved in the shaping of responses (Saboga-Nunes et al., 2020). Indeed, there is no question about the way people's personal lives and relationships have been reconfigured by the Internet, social media and digital devices. Building on the 1980 WHO Health for All strategy, the 1986 Ottawa Charter was explicit on harnessing and establishing healthy settings, where people actively use and shape the environment for better health ('Creating Environments Conducive to Health', 1986). Settings are identified as having physical boundaries, people with defined roles and organizational structures (Poland et al., 2009). This was a critical step towards the integration of health promotion and sustainable development (Wailberg et al., 2021). In an increasingly digital world, one's digital life can be identified as a setting, and the need for a multi-sectoral approach is a pressing perspective (Dorner et al., 2018).

Worldwide, the value and use of digital devices to support both medical, social and public health practice and research are increasingly being appreciated (Blaya et al., 2010; Olu et al., 2019; WHO, 2019). The use of digital health technologies has been embraced as a way to promote health and wellbeing through access to vital health services. In April 2019,

L. Saboga-Nunes $(\varangle)$

Institute of Sociology, University of Education Freiburg,

Breisgau, Germany

Coimbra Health School, Coimbra, PC, Portugal

e-mail: luis.saboga-nunes@ph-freiburg.de

U. H. Bittlingmayer

Institute of Sociology, University of Education Freiburg,

Breisgau, Germany

P. Bakibinga

African Population and Health Research Center, Nairobi, Kenya the World Health Organization released the first guidelines on digital health interventions, valued for their potential to reduce health inequities and inequalities (WHO, 2019). The COVID-19 pandemic has resulted in disruptions in health services' delivery in many settings (WHO, 2020a). As such, in the responses, the WHO has called for digitalization of health service delivery in a bid to ensure continuity of healthcare delivery in a manner that protects both frontline health workers and the patients they serve (WHO, 2020b). Over the last decade, there has been global enthusiasm and interest among development agencies, researchers and policymakers resulting in the rapid proliferation of digital health promotion (DHP) solutions in many countries (Saboga-Nunes, 2013). Such solutions are appreciated for their ability to transcend physical and, to a certain extent, financial barriers and thus reducing health inequities (Boa-Ventura \& Saboga-Nunes, 2010; Olu et al., 2019). To reduce inequities and inequalities, digital technologies must be able to demonstrate long-term improvements over the traditional ways of delivering health services (WHO, 2018, 2019). However, the evidence base for reporting of DHP interventions is heterogeneous in quality, completeness and objectivity, making comparisons across intervention strategies difficult (Olu et al., 2019). This is because DHP lacks a firm theoretical foundation (Iyawa et al., 2016). There is a need to develop a conceptual framework to advance this growing field. Existing conceptual frameworks have focused mainly on reporting and evaluation of digital health technologies in health promotion settings (Iyawa et al., 2016; Kowatsch et al., 2019). Furthermore, many digitized health promotion strategies have been criticized for dwelling on one's responsibility for health without appreciating the role that social, cultural, economic and political influences have on the use of digital technology (Lupton, 2014). Also, new perspectives have been added to this discussion like the discussion of health literacy and health promotion (where digital health literacy, critical health literacy, among others are included) (Saboga-Nunes et al., 2019).

Antonovsky's salutogenic model and its core concept 'sense of coherence' (SOC) focus on the ability of individu- 
als to cope with stressors in life and stay healthy (Antonovsky, 1987, 1996). Salutogenesis, a positive resource for health, has a lot of promise in the development and implementation of digital health interventions, many of which centre on selfcare. We posit that digital life is a generalized resistance resource (GRR) onto which specific interventions can be harnessed as specific resistance resources (SRRs) that can be harnessed to improve population well-being and survival.

Against this background, here we explore the potential of salutogenesis to support development in one's digital lifeworld as well as its potential to inform better digital health promotion initiatives, especially in low-resource settings.

\section{The Digital Lifeworld Formally Defined}

The digital lifeworld (German: Lebenswelt) (Husserl, 1970) has, for many of us, become a fundamental aspect of one's whole life experience. Therefore, the search for the answer to the salutogenic question "what explains movement towards the health end of the health/illness continuum?' leads us to the study of the digital lifeworld as a lifeworld where resistance resources (RR) - and the SOC in particular - may be shaped, activated or degraded. The SOC and its constituents (Fig. 56.1) are not a coping strategy, they are a broad orientation to life. The salutogenic hypothesis is that the stronger the SOC, the greater the likelihood of moving towards the health end of the continuum.

Aaron Antonovsky (1990) wrote that 'the important determinants of the SOC are to be found in the nature of the society in which one lives in a given historical period, and the particular social role complexes in which one is embedded'. With the advent of the digital lifeworld, a new historical period is upon us, carrying new, complex social roles that no one can escape. Currently, a life disconnected from the digital lifeworld is almost impossible. But if that were to happen in the life of a person, that is, become excluded from the digital lifeworld, then the digital lifeworld would become a generalized resistance resource deficit (GRR-D). Therefore, the digital lifeworld is among the many roads to a strong SOC.
Fig. 56.1 The digital lifeworld inter-occurrences. (Source: Adapted from Saboga-Nunes (2012). With permission of $\odot$ Escola Nacional de Saúde Pública. All rights reserved)

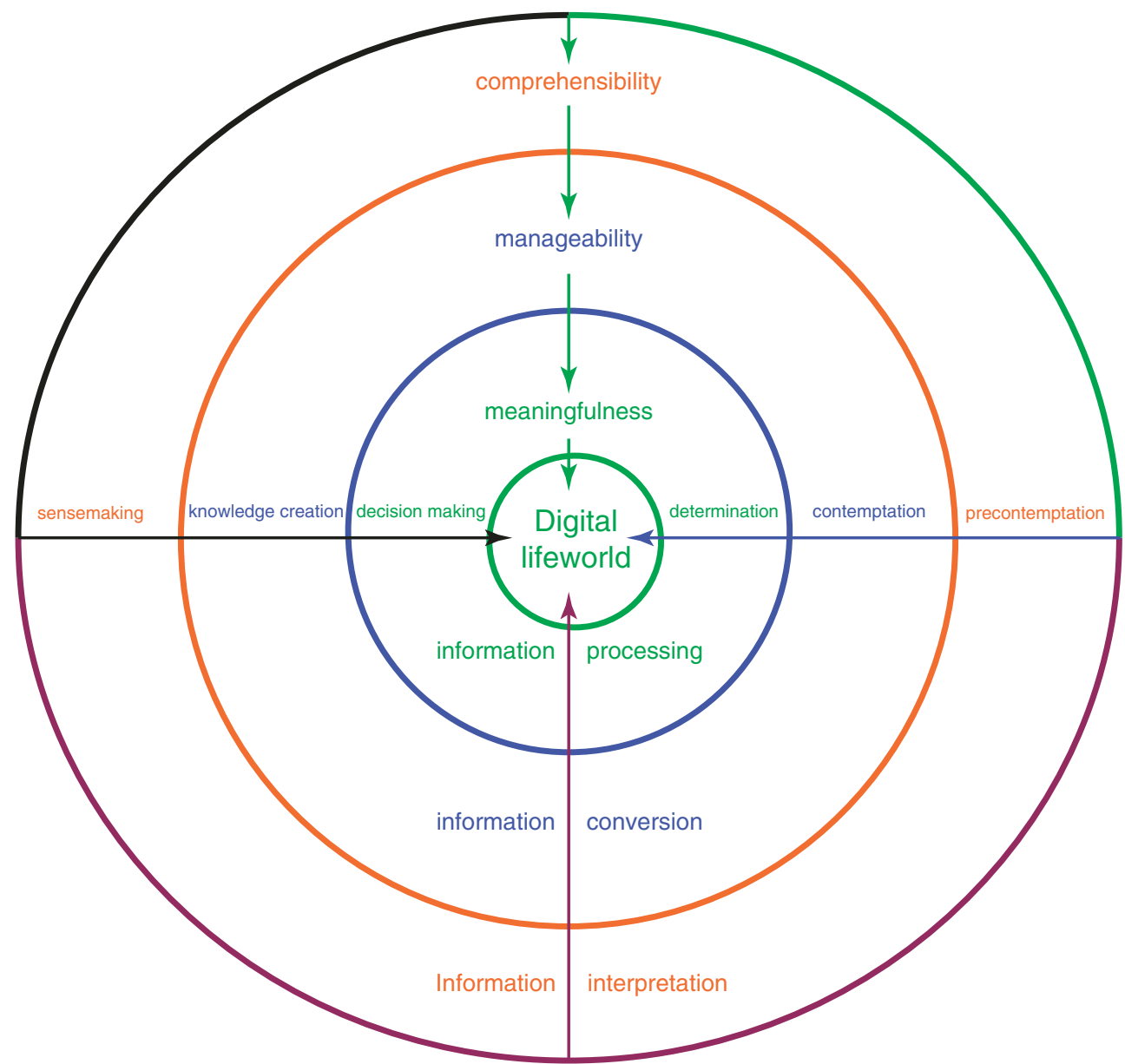




\section{The Origins, History and Trajectory of the Digital Lifeworld: From Information Technology to a New Lifeworld of Social Interaction}

Expressions such as the 'World Wide Web', 'e-mail', 'Internet of things', 'AI: artificial intelligence' are today so much taken for granted that nobody questions their pervasive and ubiquitous para-existence (Hopkins \& Crowell, 2015, p. 172), and they constitute a significant general resistance resource. The advent of the 'information age' carries with it innovative opportunities for health promotion, providing new implementation tools.

\section{The Emergence of the Digital Lifeworld as Important in the Salutogenic Model of Health}

Digital life emerges from the exponential growth of information and knowledge communication technologies (IKCT), allowing for the development of IKCT-mediated health promotion tools. This growth has been made possible because of the computer revolution and the democratization of the World Wide Web (WWW), from strictly military to public purposes, giving birth to a significant general resistance resource. Patterns drive the Internet. These patterns lead to trends that are less sensitive to individual needs. These trends, based on algorithms, are machine-based learned that increase the lack of control by the person user. Therefore, three domains of this lifeworld may directly affect comprehensibility, manageability and meaningfulness. This suggests we expand the salutogenic model of health to the left, amplifying the socio-cultural and historical context (Fig. 56.2). We could, therefore, find at least three phases in this tension between the (previously referred) two poles (patterns vs. tailoring): information interpretation, information conversion and information processing, before activating any action towards health promotion in the DGW (see Fig. 56.1).

\section{The Digital Lifeworld as a Source of GRRs}

The digital lifeworld is a major GRR. If a person is excluded of the digital lifeworld, then we have the digital lifeworld as a GRR-D. The digital lifeworld is built according to patterns (e.g. number of 'likes' will exclude or upgrade an information). These patterns are structured according to a specific user profile (tailoring process) that tunnels to a specific user a bunch of specific information. Because of the ubiquity of the digital lifeworld there is a polarization process: on one side the individual wants to be active, an actor in control. Nevertheless because of the patterns originated on the tailoring process he or she is excluded from this active role being the object of a machine learning automation.

Without a strong SOC, the individual may face high entropy in the digital lifeworld, that is, move towards the disease end of the continuum. Moving on the continuum from the pole of a higher level of entropy (higher level of chaos) to the pole of a lesser level of entropy is a challenge for every person.

To grapple with chaos, the individual needs to be able to interpret information, convert information to be applied into her or his everyday experiences and consequently acquire a level of information processing that originates order and not chaos. These three stages of information management have strong connections with the three dimensions of the SOC: comprehensibility, manageability and meaningfulness (Fig. 56.1).

\section{The Digital Lifeworld as a Source of SRRs}

This is where the role of specific resistance resources (SRRs) that can be defined as the 'instrumentalities whose meanings are defined in terms of the particular stressors they are invoked to manage' (Mittelmark et al., 2016) is highlighted.

For Antonovsky, What the person with the strong SOC does is ... [choose] from the repertoire of generalized and specific resistance resources at his or her disposal... (Antonovsky, 1987, p. 138).

The critical question, then, is how the digital lifeworld empowers individuals with SRRs (and for those excluded with SRR-D)? Is the digital lifeworld an 'appropriate social condition', or in Antonovsky's words, supportive of health?

\section{The SOC Balancing New Information}

The digital lifeworld can be compared to a well-organized library that is continually receiving new 'books'. This creates new challenges to maintain low entropy, as a result of the incremental changes in the digital lifeworld. To cope with this change, the strong-SOC person seeks a balance ..., between stored and new information. There is confidence that sense can be made of the new (information) (Antonovsky, 1987, p. 28). This way, the overload of potential information that the digital lifeworld impinges on us can be handled in a way that will help keep that healthy balance. 


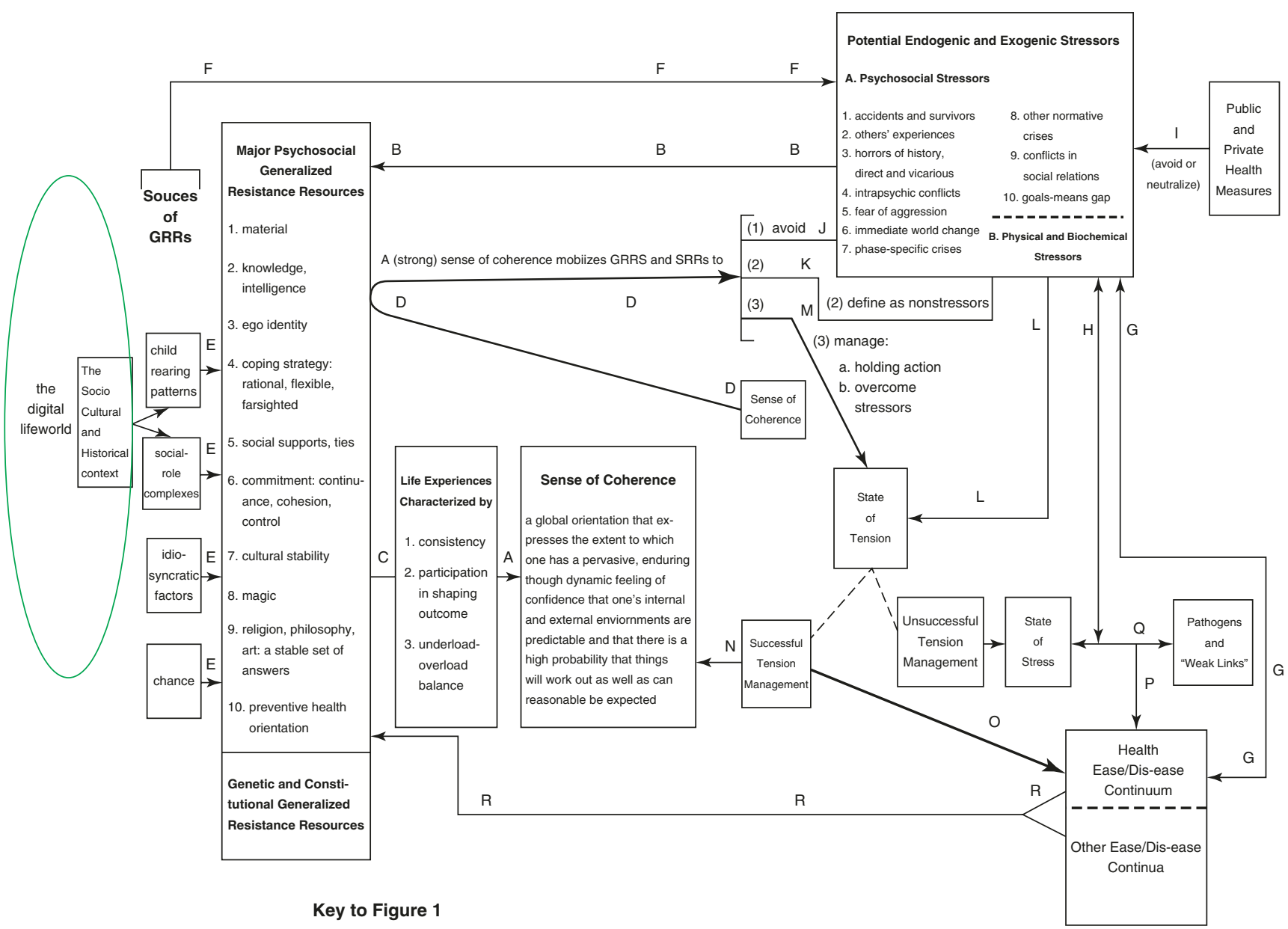

Arrow A: Life experiences shape the sense of coherence.

Arrow B: Stressors affect the generalized resistance resources at one's disposal. Line C: By definition, a GRR provides one with sets of meaningful, coherent life experiences.

Arrow D: A strong sense of coherence mobllizes the GRRs and SRRs at one's disposal.

Arrows $\mathrm{E}$ : Childrearing patterns,social role complexes, idiosyncratic factors, and chance build up GRRs.

Arrow F: The sources of GRRs also create stressors.

Arrow G: Traumatic physical and biochemical stressors affect health status directly; health status affects extent of exposure to psychosocial stressors.

Arrow H: Physical and biochemical stressors interact with endogenic pathogens and "weak links" and with stress to affect health status.

Arrow I: Public and private health measures avoid or neutralize stressors.

Line J: A strong sense of coherence,mobilizing GRRS and SRRs, avoids stressors.

The salutogenic model of health Antonovsky's 1979 book.
Line K: A strong sense of coherence,mobilizing GRRS and SRRs, defines stimuli as nonstressors.

Arrow L: Ubiquitous stressors create a state of tension.

Arrow M: The mobilized GRRs (and SRRs) interact with the state of tension and manage a holding action and the overcoming of stressors.

Arrow N: Successful tension management strengthens the sense of coherence.

Arrow O: Successful tension management maintains one's place on the health ease/dis-ease continuum.

Arrow P: Interaction between the state of stress and pathogens and "weak links" negatively affects health status.

Arrow Q: Stress is a general precursor that interacts with the existing potential endogenic and exogenic pathogens and "weak links."

Arrow R: Good health status facilitates the acquisition of other GRRs.

Note: The statements in bold type represent the core of the salutogenic model.

Fig. 56.2 The salutogenic model of health. (Source: Adapted from Antonovsky (1979, pp. 184-185). Published with permission of @ Avishai Antonovsky, 1979. All rights reserved)

\section{The SOC as a Factor in Coping with the Digital Lifeworld}

The configuration of the digital lifeworld could set the stage for increased entropy, thus jeopardizing health. One example referred to by Antonovsky is inconsistency and lack or excess of information. The digital lifeworld is characterized by inconsistency and excess of information, characteristics that may contribute to 'exclusion from participation in decision making’ (Antonovsky, 1987, p. 28).

This is most common when, for example, a new update for an operating system (OS) or a browser invades a person/ 
citizen's digital lifeworld without direct control from him. Facing new tools, functions or layouts can become intensively stressful for the user. What makes the citizen of the digital lifeworld embrace a conversion process, adapt and upgrade himself to fit the new challenge of the digital lifeworld? The salutogenic answer could be his or her SOC.

We are all, in one way or another, confronted permanently with change in the digital lifeworld. This causes disequilibrium that Antonovsky calls heterostatic disequilibrium (Antonovsky, 1987, p. 131) and this state is at the heart of the salutogenic orientation. Therefore, as the digital lifeworld evolves so rapidly, new stressors introduce entropy and GRRs and SRR introduce negentropy into the human system and that 'one's SOC orchestrates this battleground of forces promoting order or disorder' (Antonovsky, 1987, p. 164).

To deal with this changing environment of the digital lifeworld, a concession between autonomy and artificial intelligence compromises the 'personhood-as-process'. The digital lifeworld could be included in the pattern specified as an open-ended and dwelling always at the edge, far from equilibrium. We encounter a decentralized, multifaceted ensemble whose coherence as a being is sustained only by its continuous becoming (p. 1206, cit in Antonovsky, 1987, p. 169). The digital lifeworld, in its essence, is a permanent call for 'becoming', enacting the actualization of the person so that identity takes shape amid a multitude of bits trying to make sense. The paradox is that to 'become', we accept the totalitarian structure of hierarchically organized units of the digital lifeworld (Antonovsky, 1987, p. 169), accepting to loose autonomy, which in the end compromises health promotion in itself. Loosing autonomy is the consequence of the artificial intelligence based on the algorithms that populate the digital lifeworld and that decrease substantially the autonomy of the 'living' in it.

This permanent need of the digital lifeworld demanding constant new feeds (like posting onto Facebook the picture of the dinner) can become a general resistance resource deficit (GRR-D), leading to unsuccessful tension management, harbouring tools that can become specific resistance resources deficits (SRR-D).

Every individual decides to manage with SRR the meaning that is retrieved out of 'becoming'. But this process is not unequivocally aimed to be a success (e.g. SRR-D). Even if the idea beyond this is the optimist claim that the Internet would change hindrances of accessibility to gods (such as information, e.g., information about health and its promotion), we still face in the digital lifeworld specific barriers to a healthy 'becoming'.

These barriers can be based on the stages of change of precontemplation, contemplation and determination to act (see Fig. 56.1). How a person moves from contemplation to action? According to the SOC dimension (e.g. comprehensibility), this can happen when the sense-making phase of information interpretation takes place. This will be followed by manageability used for information conversion towards knowledge creation. Determination to 'become' in the digital lifeworld is rooted in the meaningfulness that is originated in decision making derived from information processing.

For Antonovsky, 'Salutogenesis, (...) leads us to focus on the overall problem of active adaptation to an inevitably stressor-rich environment (such as the digital lifeworld) while moving away from chaos' (Antonovsky, 1987, p. 169). This active adaptation will only be a success if the creation of health in the digital lifeworld is achieved in a partnership between citizens, software developers, health promoters, public health managers (to name a few examples) in a coproduction and creation process.

\section{The Digital Lifeworld as a Setting for Health Promotion: An Example in the Health Promotion Arena of Tobacco Control}

If smoking is considered a 'disease', how smoking is to be cured? In the pathogenesis context, the treatment process is standardized and monitored in the conventional doctor's five-stage work model: (i) measure, (ii) detect (abnormality), (iii) prescribe (treat), (iv) measure (normality) and (v) end intervention. According to this model, the treatment process for the smoker also has five stages, as the parameter to be measured is blood carbon monoxide (CO) levels.

Ultimately, when a condition such as hypercarboxyhaemoglobinaemia is detected, one must ask if the model described earlier is appropriate for terminating or 'curing' the 'disease' of smoking. Unfortunately, the pathogenesis armamentarium to cure smoking and lead to successful smoking cessation is beyond expectations (Saboga-Nunes et al., 2017).

Therefore, another pathway to look at smoking and smoking cessation is from health promotion and the salutogenesis entry point.

Tobacco use is one prized mechanism for fighting social entropy (in a first stage) before it is used to regulate physical and psychological entropy (after nicotine addiction has been established). Many of those who take up the use of tobacco do it for a reason that can be expressed in the equation of the number of friends who no longer will go along because a person refuses to use tobacco (Baker et al., 2004).

On the one hand, the fight against chaos is based on smoking (not to lose friends, and be part of the group), while on the other hand, nicotine addiction increases life chaos with unending withdrawal symptoms.

Once the self reaches this awareness (with knowledge creation), very often the individual is ready to consider quitting and return to the previous state of a non-smoker. This process is poorly managed by the pathogenic approach to smoking cessation. 
Despite this, quit smoking continues to be emphasized, but the uptake of cessation assistance has exceeded the capacity of services in several countries (showing the shortsightedness of the pathogenesis road to life again without tobacco). This is a context to look for another model of health, and consider the potential of digital lifeworld to increment health literacy as a means of empowering people to make behavioural changes (Saboga-Nunes et al., 2019). Also, the trade-off on the use of the digital lifeworld (as a GRR) as a mean to distribute a tool (as an SRR) for smoking cessation [it can reach a vast number of people for a small cost (efficiency)] demonstrating to work in the domain of smoking cessation (efficacy) is worth to be considered.

The fundamental question is, can health promotion and salutogenesis help a smoker quit?

There are different approaches to the problem of people being swept along in the river [a metaphor often used by Antonovsky that compared life to a river (Antonovsky, 1987, p. 90)]. The 'river' could be the smoking behaviour: they can be rescued before drowning, they can be prevented from entering the river by fences or walls, they can be taught how to swim and be rescued before exhaustion. The possibilities vary according to the many health models and theories (for better health or less disease) that can be implemented.

From the salutogenic perspective, starting a smoking cessation process can happen 'in the river of life', that is, amidst all life experiences. With their particular SRR, smoking cessation can be set as an aim despite prevailing conditions. It is, therefore, important to understand how the personality disposition that Antonovsky called the SOC allows people to survive in the water. The normal condition is not balance and health (in the sense of the WHO definition of health), but imbalance, which leads to suffering and sometimes to disease. Therefore, here we have a major difference to support smoking cessation: in the salutogenesis perspective, a smoker does not have to be in a state of positive stress management (as it is said, with low stress) to start a smoking cessation process.

To cope well, people's readiness and willingness to exploit the resources that they have at their potential disposal (Antonovsky, 1984, p. 121) is essential, and that could be based at the digital lifeworld.

In this context, it is essential to believe that the input from one's digital lifeworld environment and the feedback is information and not 'noise' or, in simple words, that life (smoking cessation) makes sense. This is called comprehensibility (Antonovsky, 1987, p. 16). The belief that stimuli make sense is ordered, structured and predictable is essential but not sufficient for the individual to cope well and stop smoking. One not only has to know the rules for stopping smoking, but must also have confidence in the resources like SRR at one's disposal.
One has to reject the idea that the cards of life are stacked against one and that, consequently, one can never stop. The stimuli, or the stressors, are always there, making demands. But if one is persuaded that a variety of appropriate resources to meet these demands are available, then that person can cope well and stop smoking. This second component of the SOC is defined as manageability (Antonovsky, 1987, p. 17). To believe that one understands what it means to stop smoking and that one can manage its process is not enough.

The motivational element is crucial. One must wish to cope with dependency and stop smoking. One must see the demands posed by the stimuli as making sense emotionally. The stimuli may be painful and sad, like the deprivation of nicotine in the brain. One can fall into despair or be determined to continue the struggle. This third component of the SOC is called meaningfulness (Antonovsky, 1987, p. 18).

An example of using salutogenesis in smoking cessation can be found at www.parar.net (Saboga-Nunes, 2012). This SRR is structured according to the acronym 'Renasceres' (Saboga-Nunes et al., 2016) (from the renaissance perspective of new birth) in a ten-step process - in which each step carries the participant through different stages towards the goal and plays a significant role of self-actualization (Fig. 56.3).

These ten steps (resiliency, exercise, nutrition, agua, sun, confidence, equilibrium, rest, empowerment and sense of coherence) are organized in two groups: (1) stop smoking awareness facilitator and a (2) relapse prevention stage (Fig. 56.3).

Therefore, this SRR is built to be a permanent interactive and tailored process, where information computation is intended to promote knowledge creation, leading the person to decision making, before becoming an active agent in his or her life changes. The core content of this SRR strategy is organized around the mnemonic and acronym renasceres in ten steps, with two major areas: (1) where diagnostic tools establish the basis for the quit attempt (step 1) and (2) relapse prevention tools (step 2 to step 10).

This SRR is composed of two sources of information. When combined, they allow information and knowledge management of a tailored smoking cessation administration process, based on a user-centric approach. It is aimed at leading the person to aim towards the ease pole of the dis-ease/ ease continuum.

The task of this SRR process is to support self-efficacy while unveiling a set of conditions that can facilitate the counselee's willingness to change, by enabling a first small step: establishing a Dday (Fig. 56.3, stage 9). The responsibility for change lies with the counselee (motivation enhancement therapy). Acceptance of small shifts in attitude as worthy of a first step in behaviour change is in accordance with principles of motivational interviewing, a mechanism 


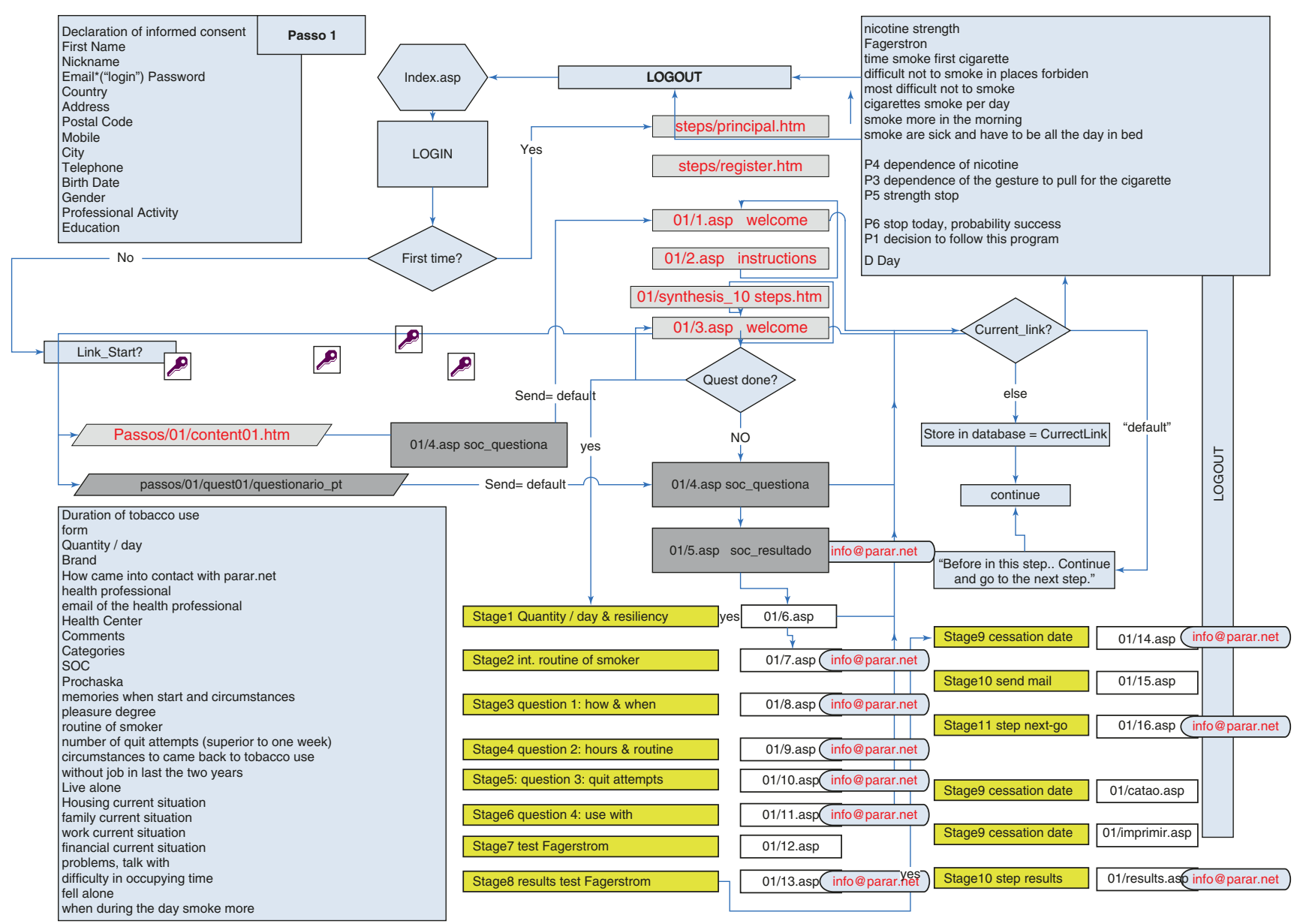

Fig. 56.3 Organogram of a strategy (step 1: resiliency) based on AI, aiming at supporting smoking cessation (parar.net). www.PARAR.net $\odot$ All rights reserved

that is commonly used to address smoking cessation (Rollnick et al., 1999). An action plan is proposed within the context of an SRR holistic lifestyle perspective (where various aspects of life are interrelated from a health promotion approach).

The concept of entropy (Rifkin \& Howard, 1980), although pessimistic, sustains the approach of Antonovsky to health promotion and has the merit of unveiling a pathway to smoking cessation. This concept is at the basis of this SRR. We live in a world that is short of resources for satisfying every human being's needs (as made explicit before within the context of smoking cessation). As a result, without proper management of existing resources, the natural consequence is non-sustainability, increased chaos and/or annihilation of life. Information and energy are examples of these resources, and the digital lifeworld is a GRR that when used may feed an individual's needs: 'The fact remains, that living organisms have the power to build up ordered, coherent perceptions and complex systems of knowledge out of the chaos of sensations impinging on them; life sucks information from the environment as it feeds on its substances and synthesizes its energies' (Koestler, 1967, p. 199).

\section{An Example of Decision Support for Low- Cadre Health Workers in Sub-Saharan Africa}

Decision support systems for community health volunteers are an example that explains how the digital lifeworld could be a GRR enabling coping in a challenging context. A decision support system tailored at responding to knowledge and skills' gaps could be an SRR.

Due to the prevailing human resources for health crisis globally, and in sub-Saharan Africa in particular, community health volunteers (CHVs) have been identified as a vital health workforce. They serve to bridge the gap between communities and households with the formal health sector. However, CHVs have limited training before they are assigned roles taking care of the basic health needs of communities. They are a critical part of the healthcare delivery 
system, especially in rural and urban poor settings where there are inadequate numbers of formally trained healthcare workers.

Research has demonstrated that CHVs can help in saving many lives if they possess the prerequisite basic skills and equipment. However, given that $\mathrm{CHVs}$ receive minimum training, they often experience challenges in making the right decisions on treatment and referral and thus delays and errors are likely to occur. CHVs also lack comprehensive health education skills. Clinical decision support systems have been shown to reduce medical errors and increase healthcare quality, so decision support systems for CHVs would go a long way in improving their efficiency and effectiveness in delivering interventions. Can salutogenesis and health promotion help a $\mathrm{CHV}$ thrive in a challenging work environment? Salutogenesis underscores one's ability to use the resources at their disposal.

Such a decision support system has been co-developed and tested with CHVs successfully by Bakibinga et al. (2017). The challenging work conditions can be understood as the 'disease'. The digital lifeworld can be seen as a GRR. The preloaded information can be seen as an SRR such that when $\mathrm{CHV}$ s encounter a health condition that is unfamiliar to them, they are supported to make the ideal decision. The information they enter and the support of the in-built algorithms enables a movement towards the ease end of the continuum. However, despite having the decision support system as a resource (SRR), to cope with specific work challenges, not all the CHVs used the system. This was, amongst other concerns, in part due to limited digital literacy/skills, limited Internet coverage and attitudes towards the system (Bakibinga et al., 2018). Although the system was developed to serve as an SRR, such challenges serve to increase inequities (Mittelmark et al., 2016). Lessons from this pilot stress the importance of understanding the individual needs of each user before they are expected to work with the system. This would serve to tailor the intervention to the needs of each individual. For instance, those with limited digital skills would benefit from some form of capacity building before such interventions are implemented. This would entail providing digital literacy training to those without adequate knowledge and skills.

Several other innovations backed by the current high and ever-growing mobile penetration in sub-Saharan Africa have been implemented (Blaya et al., 2010). These are equally supported by investments from technology companies that provide accessible platforms onto which innovations can establish and offer value-based products that can be harnessed to improve population well-being and survival. Innovations have been implemented to support medication adherence, health education, health worker communications, e-health, emergency disaster responses, among others (Folaranmi, 2014). For most digital health interventions, like other health initiatives, they have traditionally been focused on responding to basic needs and/or modifying lifestyle behaviours.

In addition, although the use of digital technologies offers new opportunities to empower and improve people's health (Folaranmi, 2014), available evidence also highlights challenges already referred to (such as weak health systems that prematurely hope to harness the potential of digital technology to improve health access, quality of health services to ultimately improve health and well-being) (Aranda-Jan et al., 2014). As the WHO reaffirms, weak health systems cannot expect to use digital health appropriately, in the path to universal health coverage (WHO, 2019). Some key challenges affecting the implementation of digital health solutions in Kenya and related settings in SSA include scarcity of steady power supply, lack of basic ICT skills by users, low network coverage, stringent government laws about access, use of social media, among others (Bakibinga-Gaswaga et al., 2020; Betjeman et al., 2013; Folaranmi, 2014). These largely reflect the social, cultural and political contexts within which interventions anchored on the digital lifeworld are implemented. Such concerns have to be attended to before digital health solutions can be fully utilized to reduce health inequities. In the responses to the COVID-19 pandemic, digital technologies have been harnessed in different sectors, including health, yet the challenges mentioned earlier make continuity service delivery impossible, thus leaving many behind (Bakibinga-Gaswaga et al., 2020).

Although salutogenesis has not been fully embraced in medicine and social science in SSA, there is a growing body of evidence showing the application of salutogenesis in understanding health and well-being of different population groups on the sub-continent (Bakibinga et al., 2012; Daniel \& Mathias, 2012; Rukundo \& Daniel, 2016). Such studies could be the backbone on which salutogenic informed digital health promotion is anchored, going forward.

\section{Conclusions and Future Directions}

Under the salutogenic framework, the digital lifeworld as a new healthy setting might unleash new GRRs and SRRs. This will not only answer the overall goal of health promotion in the pursuit of the origins of health, but it will also impact disease prevention and cure. This has been made more evident during the COVID-19 pandemic, with many being left behind, especially in low-resource settings as those in sub-Saharan Africa. Salutogenesis has the potential to redefine and guide digital health promotion programs while reducing health inequities. Integration of salutogenesis with digital health promotion in sub-Saharan Africa, as elsewhere, would be possible and serve to ensure better health and wellbeing for populations. 
Before this is achieved, there are two steps necessary, for academia, policy and practitioners. First, appreciation of positive health and resources in research, policy and practice is necessary. As most of the current research on salutogenesis is situated in the West, we need more collaborative international research to advance the knowledge base for guidance of digital health programs. Second, digital health interventions need to focus more on empowering users to take charge of their health and well-being as well as paying attention to the social, cultural and political dimensions of digital technology.

\section{References}

Antonovsky, A. (1979). Health, stress, and coping: New perspectives on mental and physical well-being. Jossey-Bass.

Antonovsky, A. (1984). A call for a new question - salutogenesis - and a proposed answer: The sense of coherence. Journal of Preventive Psychiatry, 2(1984), 1-13.

Antonovsky, A. (1987). Unraveling the mystery of health: How people manage stress and stay well. Jossey-Bass.

Antonovsky, A. (1990). Studying Dis. Studying health, lecture at the congress for clinical psychology and psychotherapy 1990 February 19, Berlin. Available at: http://www.angelfire.com/ok/soc/aberlim. html. Accessed 20 Jan 2020.

Antonovsky, A. (1996). The salutogenic model as a theory to guide health promotion1. Health Promotion International, 11(1), 11-18. https://doi.org/10.1093/heapro/11.1.11

Aranda-Jan, C. B., Mohutsiwa-Dibe, N., \& Loukanova, S. (2014). Systematic review on what works, what does not work and why of implementation of mobile health (mHealth) projects in Africa. BMC Public Health, 14(1), 188. https://doi. org/10.1186/1471-2458-14-188

Baker, T., Brandon, T., \& Chassin, L. (2004). Motivational influences on cigarette smoking. Annual Review of Psychology, 55(2004), 463-491.

Bakibinga, P., Kamande, E., Kisia, L., \& Omuya, M. (2018). Report of the 2017 end-line survey for the community health volunteers' decision support system project. Retrieved from Nairobi: https://aphrc. org/wp-content/uploads/2019/07/CICF-CHV-DSS-Report-draft11. pdf.

Bakibinga, P., Kamande, E., Omuya, M., Ziraba, A. K., \& Kyobutungi, C. (2017). The role of a decision-support smartphone application in enhancing community health volunteers' effectiveness to improve maternal and newborn outcomes in Nairobi, Kenya: Quasiexperimental research protocol. BMJ Open, 7(7), e014896. https:// doi.org/10.1136/bmjopen-2016-014896

Bakibinga, P., Vinje, H., \& Mittelmark, M. (2012). Self-tuning for job engagement: Ugandan nurses' self-care strategies in coping with work stress. International Journal of Mental Health Promotion, 14(1), 3-12. https://doi.org/10.1080/14623730.2012.682754

Bakibinga-Gaswaga, E., Bakibinga, S., Bakibinga, D. B., \& Bakibinga, P. (2020). Digital technologies in the COVID-19 responses in sub-Saharan Africa: Policies, problems and promises. The Pan African Medical Journal, 35(2), 38. https://doi.org/10.11604/pamj. supp.2020.35.2.23456

Betjeman, T. J., Soghoian, S. E., \& Foran, M. P. (2013). mHealth in sub-Saharan Africa. International Journal of Telemedicine and Applications, 2013, 7. https://doi.org/10.1155/2013/482324
Blaya, J. A., Fraser, H. S. F., \& Holt, B. (2010). E-health technologies show promise in developing countries. Health Affairs, 29(2), 244-251. https://doi.org/10.1377/hlthaff.2009.0894

Boa-Ventura, A., \& Saboga-Nunes, L. (2010). "Biographic spaces": A personalized smoking cessation intervention in second life. In International conference, 18, Big Island, HI, USA, June 2010-User modeling, adaptation and personalization (pp. 415-418). SpringerVerlag. With Boa-Ventura, A. - http://dl.acm.org/citation.cfm?id=21 49528\&picked=prox \&CFID $=119371290 \&$ CFTOKEN $=40862578$.

Creating Environments Conducive to Health. (1986). Health. Promotion International, 1(4), 453-455. https://doi.org/10.1093/ heapro/1.4.453

Daniel, M., \& Mathias, A. (2012). Challenges and coping strategies of orphaned children in Tanzania who are not adequately cared for by adults. African Journal of AIDS Research, 11(3), 191-201. https:// doi.org/10.2989/16085906.2012.734978

Dorner, T., Saboga-Nunes, L., \& Paget, D. (2018). Editorial: Health promotion and the need for a multisectoral approach. European Journal of Public Health, E-Collections. https://academic.oup.com/ eurpub/pages/health_promotion

Folaranmi, T. (2014). mHealth in Africa: Challenges and opportunities. Perspectives in Public Health, 134(1), 14-15. https://doi. org/10.1177/1757913913514703

Hopkins, B., \& Crowell, S. (2015). The new yearbook for phenomenology and phenomenological philosophy (Vol. 2, p. 172). Routledge.

Husserl, E. (1970). The crisis of European sciences and transcendental phenomenology. An introduction to phenomenological philosophy. Northwestern University Press.

Iyawa, G. E., Herselman, M., \& Botha, A. (2016). Digital health innovation ecosystems: From systematic literature review to conceptual framework. Procedia Computer Science, 100, 244-252. https://doi. org/10.1016/j.procs.2016.09.149

Koestler, A. (1967). The ghost in the machine. Arkana.

Kowatsch, T., Otto, L., Harperink, S., Cotti, A., \& Schlieter, H. (2019). A design and evaluation framework for digital health interventions. IT - Information Technology, 61, 253.

Lupton, D. (2014). Health promotion in the digital era: A critical commentary. Health Promotion International, 30(1), 174-183. https:// doi.org/10.1093/heapro/dau091

Mittelmark, M. B., Bull, T., Daniel, M., \& Urke, H. (2016). Specific resistance resources in the Salutogenic model of health. In M. B. Mittelmark, M. Eriksson, et al. (Eds.), The handbook of Salutogenesis [Internet] (Vol. 2017). Springer.

Olu, O., Muneene, D., Bataringaya, J. E., Nahimana, M.-R., Ba, H., Turgeon, Y., Karamagi, H. C., \& Dovlo, D. (2019). How can digital health technologies contribute to sustainable attainment of universal health coverage in Africa? A perspective. Frontiers in Public Health, 7(341). https://doi.org/10.3389/fpubh.2019.00341

Poland, B., Krupa, G., \& McCall, D. (2009). Settings for health promotion: An analytic framework to guide intervention design and implementation. Health Promotion Practice, 10(4), 505-516. https://doi. org/10.1177/1524839909341025

Rifkin, J., \& Howard, T. (1980). Entropy: A new world view. Viking Press. isbn:0-670-29717-8.

Rollnick, S., Mason, P., \& Butler, C. (1999). Health behaviour change: A guide for practitioners. Churchill Livingstone.

Rukundo, P., \& Daniel, M. (2016). Children orphaned by AIDS in Uganda: Can they thrive under orphanage care. Social Work and Society, 14(1), 1-17.

Saboga-Nunes, L. (2012). Web-Assisted Tobacco Intervention in Portuguese: Intentions to make behavioural changes and behavioural changes Specialisation in Public Health. Universidade NOVA de Lisboa. Available at: http://hdl.handle.net/10362/9898. Accessed 20 Jan 2020. 
Saboga-Nunes, L. (2013). Distant learning training on health information and knowledge management. In Working group on innovation and good practice in public health education - ASPHER. Modern teaching: Distance learning: A guide to online and blended learning with case studies from public health (pp. 104-105). ASPHER.

Saboga-Nunes, L., Bittlingmayer, U. H., \& Okan, O. (2019). Salutogenesis and health literacy: The health promotion simplex! In O. Okan, U. Bauer, D. Levin-Zamir, P. Pinheiro, \& K. Sørensen (Eds.), International handbook of health literacy. Research, practice and policy across the lifespan. The Policy Press, University of Bristol.

Saboga-Nunes, L., Freitas, O., \& Cunha, M. (2016). Renasceres: Um modelo para a construção da cidadania em saúde através da literacia para a saúde. Revista Servir, 59(1), 7-16.

Saboga-Nunes, L., Levin-Zamir, D., Bittlingmayer, U., Contu, P., Pinheiro, P., \& Ivassenko, V. et al. (2020) A health promotion focus on COVID-19: Keep the Trojan horse out of our health systems. Promote health for ALL in times of crisis and beyond!: EUPHA-HP, IUHPE, UNESCO Chair Global Health \& Education. Available from: https://www.iuhpe.org/images/IUHPE/Advocacy/COVID19_ HealthPromotion.pdf..

Saboga-Nunes, L., Levin-Zamir, D., \& Rabius, V. (2017). Tobacco still a major killer - will we achieve the end game? European Journal of Public Health, 27-4, 22-25. https://doi.org/10.1093/eurpub/ckx161
Wailberg, A., Saboga-Nunes, L., \& Stock, C. (2021). Are we there yet? Use of the Ottawa Charter action areas in the perspective of European health promotion professionals. Journal Public Health (Berlin), 29, 1-7. https://doi.org/10.1007/s10389-019-01108-x

Whitelaw, S., Mamas, M. A., Topol, E., \& Van Spall, H. G. C. (2020). Applications of digital technology in COVID-19 pandemic planning and response. The Lancet Digital Health, 2(8), e435-e440. https://doi.org/10.1016/S2589-7500(20)30142-4

WHO. (2018). Classification of digital health interventions v1.0: A shared language to describe the uses of digital technology for health. Retrieved from https://apps.who.int/iris/bitstream/handle/10665/260480/WHO-RHR-18.06-eng.pdf..

WHO. (2019). WHO guideline: Recommendations on digital interventions for health system strengthening (Vol. Licence: CC BY-NC-SA 3.0 IGO). World Health Organization.

WHO. (2020a). Pulse survey on continuity of essential health services during the COVID-19 pandemic: Interim report, 27 August 2020.

WHO. (2020b). Rolling updates on coronavirus disease (COVID-19). Retrieved from https://www.who.int/emergencies/diseases/ novel-coronavirus-2019/events-as-they-happen

Open Access This chapter is licensed under the terms of the Creative Commons Attribution 4.0 International License (http://creativecommons. org/licenses/by/4.0/), which permits use, sharing, adaptation, distribution and reproduction in any medium or format, as long as you give appropriate credit to the original author(s) and the source, provide a link to the Creative Commons license and indicate if changes were made.

The images or other third party material in this chapter are included in the chapter's Creative Commons license, unless indicated otherwise in a credit line to the material. If material is not included in the chapter's Creative Commons license and your intended use is not permitted by statutory regulation or exceeds the permitted use, you will need to obtain permission directly from the copyright holder. 